\section{Formação, investigação}

e ética científica

- caminhos da internacionalização...

Mesmo que não conheças nem o mês nem o lugar caminha para o mar pelo verão

RUY BELO

\section{AUTOR:}

António Marques ${ }^{1}$

${ }^{1}$ Faculdade de Desporto, Universidade do Porto, Portugal

https://doi.org/10.5628/rpcd.21.S1.19
Promover a excelência

no ensino e na investigação:

Um novo impulso

à internacionalização

Documento de orientação estratégica, solicitado pela Direção da FADEUP: Porto, 24 de Julho de 2017

\title{
INTRODUÇÃo
}

Com a publicação recente, por dois dos três mais conceituados rankings (ARWU e QS), das posições das universidades na área da ciência do desporto, a Faculdade teve pela primeira vez uma informação objectiva sobre a forma como é avaliada externamente. E, de forma talvez surpreendente, dessa avaliação resulta o posicionamento da Faculdade entre as 15 primeiras escolas europeias e as 50 primeiras do mundo num registo que supera, quer as posições nestes rankings da Universidade do Porto, quer as das suas escolas tomadas individualmente.

Não obstante a controvérsia existente sobre os rankings, a informação por eles proporcionada está a ajudar as universidades nos processos de análise, planeamento estratégico e definição de políticas (1), com implicações sobre a sua organização e funcionamento $(2,3)$.

De acordo com a EUA - European University Association, a internacionalização é o aspecto que mais tem influenciado a estratégia das universidades nos últimos anos (4). Por isso, e sem esquecer que a Faculdade sempre fez da internacionalização um dos pilares do seu projeto, faz sentido olhar para a informação que os rankings nos trazem e procurar compreender de que forma nos pode ajudar a desenhar o futuro.

O que deve ser feito para revalorizar o projeto de edificação de escola que iniciámos há 40 anos, em cumprimento do desígnio que assumimos de estar sempre entre as melhores?

Este é um documento de orientação estratégica que procura aproveitar o "empurrão" dado pelos rankings para consolidar a posição da Faculdade como escola de referência mundial. 
Um documento em que se procura fazer uma reflexão sobre as políticas e os instrumentos que poderão trazer um novo alento ao ensino e à investigação, no sentido da excelência. Trata-se de aproveitar as oportunidades que temos para as converter em novos avanços. Os desafios não serão pequenos, mas temos provado ter capacidade de os superar.

Este documento tem em consideração: (i) o percurso da Faculdade ao longo dos últimos anos; (ii) a estratégia da Universidade do Porto para a internacionalização; e (iii) as linhas de orientação adoptadas por universidades e associações de universidades nos países mais desenvolvidos.

\section{ONDE CHEGÁMOS?}

A Faculdade apresenta já indicadores que a consagram como uma escola com um relevante impacto internacional. Isso pode ser confirmado na ciência, no ensino e nos fluxos de estudantes, de docentes e de investigadores.

Se na investigação se pode considerar que a Faculdade é já um ator global, com colaboração com centros de investigação e universidades de 41 países nos 5 continentes e com $59 \%$ dos seus documentos citáveis publicados com colaboração internacional, no ensino é menos notória essa projeção internacional e a escola não se constituiu ainda, pela qualidade e reputação dos seus cursos, num polo de atração de estudantes internacionais. Não obstante, a presença de um significativo número de estudantes (16.1\%) estrangeiros em todos os ciclos de estudo e a colaboração regular de docentes estrangeiros, em particular, nos cursos de pós-graduação, confirmam a existência de um percurso que denuncia preocupações desse tipo.

Foram indicadores como estes que influenciaram a avaliação realizada pelas agências que elaboram os rankings e permitiram à Faculdade atingir níveis de notoriedade internacional nunca antes conseguidos.

\section{INVESTIR NA INTERNACIONALIZACÃO}

Porquê a aposta no reforço da cooperação internacional? 0 que está a motivar o esforço de abertura ao mundo das universidades nesta era da globalização?

Faz sentido deitar um olhar às principais tendências na internacionalização das universidades, das quais destacaríamos pela sua relevância:

(1) Uma grande mobilidade internacional de estudantes, determinada por uma revolução científica e tecnológica que está a abrir novas possibilidades de desenvolvimento nas sociedades e a criar uma demanda sem precedentes no acesso à educação superior (5) Também as economias emergentes, em desenvolvimento, têm vindo a colocar a educação no centro das suas prioridades, com repercussão na expansão dos sistemas de ensino superior e numa mobilidade acrescida de estudantes internacionais (6).

É, igualmente, grande o esforço de atração dos melhores investigadores. Na forte competição, que tem vindo a crescer nos últimos anos, entre os sistemas de ensino superior e entre as próprias IES - Instituições de Ensino Superior (7) uma atenção importante tem vindo a ser consagrada à atração de investigadores com talento, pois dela dependem não só a possibilidade de desenvolvimento de projetos científicos e os financiamentos que the estão associados, como, também, a melhoria de posições nos rankings internacionais de universidades.

Interessa também saber que esses fluxos de mobilidade de estudantes e investigadores estão a ser muito determinados pela reputação das universidades, pela qualidade da educação, e pelo prestígio e ambientes de trabalho dos melhores centros de investigação.

(2) Uma abordagem integrada da internacionalização: a internacionalização está a mudar o mundo do ensino superior e a globalização está a mudar o mundo da internacionalização, com esta a tornar-se central à missão das universidades e a assumir uma dimensão mais sistémica e não apenas centrada na mobilidade de estudantes (8). Por isso, cada vez mais IES estão a desenvolver uma abordagem da internacionalização que envolve também o ensino e a investigação, através de parcerias estratégicas e acordos de cooperação para o ensino, a investigação e a capacitação de recursos. Neste contexto, uma maior atenção está a ser conferida pelas IES à mobilidade de docentes e de investigadores, pela sua importância instrumental na concretização dessa estratégia (4).

(3) Promoção da excelência no ensino e na investigação: A internacionalização das universidades está a ser entendida, cada vez mais, como um pressuposto essencial da qualidade da educação superior e da investigação (9). De facto, "tal como na investigação, em que a participação em parcerias nacionais e internacionais foi um factor indutor de grandes avanços na ciência em ambientes fortemente competitivos, também na educação a melhoria da qualidade dos programas oferecidos pelas universidades está cada vez mais associada à participação em consórcios nacionais e internacionais que integrem as melhores capacidades e recursos disponíveis em cada universidade" (10).

Neste contexto, estão a ser criadas redes de universidades em posições de liderança, que compartilham os mesmos valores de elevada qualidade no ensino e na investigação realizados em ambientes de investigação muito competitivos a nível internacional, as quais procuram vias de colaboração e de comparação das suas atividades. A pertença a estas redes tornou-se um marcador de reputação, uma vez que estas universidades procuram aumentar a sua competitividade e prestígio através de tais afiliações (4). Melhorar a reputação e a confiança é, por isso, um objectivo central à estratégia das IES e o estabelecimento de parcerias para a cooperação está a ser, cada vez mais, determinado pela reputação das instituições e pela confiança que estas inspiram na prossecução das suas atividades (10). 
Neste contexto, as iniciativas das IES para a promoção da excelência e para a cooperação estratégica estão a privilegiar a criação, estruturação e consolidação de plataformas de cooperação, com particular destaque para o estabelecimento de consórcios e de redes colaborativas.

É importante dizer-se que os acordos de cooperação bilaterais, que têm constituído um dos principais instrumentos de mediação na cooperação internacional entre IES, não esgotaram o seu ciclo. Todavia, apesar de ainda muito valorizados em instituições que iniciaram mais recentemente os seus processos de internacionalização, muitos dos convénios de cooperação com IES de países em desenvolvimento são acordos de cortesia e servem sobretudo, objetivos de projeção da notoriedade internacional.

Estes convénios bilaterais continuam a ter importância para escolas como a nossa, não só pelo contributo que dão para a consolidação da sua projeção internacional, mas também como instrumentos que facilitam a mobilidade de estudantes. Dito isto, na celebração destes acordos faz sentido ponderar (10): (i) Os seus custos em recursos materiais e humanos; (ii) os benefícios esperados para a instituição; (iii) as prioridades; e (iv) a sua adequação às orientações estratégicas.

(4) Encontrar meios complementares de financiamento é uma condição de desenvolvimento das atividades de uma universidade, em particular da investigação, e da sua projeção internacional. Ora, o sucesso na angariação de recursos depende em grande medida da participação em projetos e consórcios muito competitivos, que incluam universidades e centros de investigação com atores muito competentes e experimentados na preparação e gestão de projetos.

Em resumo

A Faculdade, em alinhamento com a estratégia para a internacionalização da Universidade do Porto, deve "eleger como elemento central da sua estratégia de cooperação internacional a construção de uma imagem baseada num rigoroso exercício de valorização da qualidade, que assegure padrões de excelência no ensino e na investigação"(10).

Esta estratégia deve envolver toda a comunidade académica, primeiro na sua discussão e aprovação, e depois na sua concretização. Num esforço que não desvalorize os necessários compromissos entre a liberdade individual e dos grupos e as exigências da afirmação institucional. Numa política de "pequenos passos" que, de forma sustentável, reoriente o projeto da Faculdade para os desafios do futuro, sem comprometer as mudanças.

Quem são os atores críticos da internacionalização?(10): “(i) Os membros da comunidade académica; (ii) A Faculdade, que pode ajudar colocando "sementes", isto é, criando alguns programas ou medidas de estímulo à cooperação quando justificado; e (iii) Os geradores de contextos e oportunidades, ou seja, as agências públicas, privadas, ou fundações que promovem programas que as universidades podem aproveitar".
E de que depende um programa de internacionalização bem sucedido?(10): (i) Da consolidação de políticas e projetos institucionais; (ii) Da mobilização da comunidade académica; (iii) De um bom conhecimento dos contextos (os quadros internos e internacionais de apoio ao desenvolvimento da investigação e do ensino superior, como por exemplo o Horizonte 2020 e o Erasmus+); (iv) Da estruturação de parcerias e programas que se inscrevam nas escolhas académicas; (v) Da criação, estruturação e consolidação de plataformas de cooperação, através de consórcios e redes".

Pensamos que o caminho da internacionalização será um desafio cada vez mais estruturante do desenvolvimento da Faculdade e encontrará tradução em: (i) Atração dos melhores estudantes; (ii) Atração de investigadores e docentes prestigiados; (iii) Parcerias com universidades e centros de investigação prestigiados; (iv) Oferta de uma formação pós-graduada com reputação internacional; e (v) Desenvolvimento de uma atividade de investigação com impacto internacional.

\section{O QUE SE PROPÕE}

A orientação estratégica para a internacionalização da Faculdade nestes últimos anos teve na lusofonia um pilar fundamental. Não se esgotou aí, como se pode perceber de uma forma muito clara na investigação, mas teve na língua portuguesa e nas relações históricas de Portugal com os países da CPLP um eixo fundamental. Foi, portanto, animada por uma intenção que se inscreve no que se chama "cooperação para o desenvolvimento".

Esta política de cooperação continua a ter resultados muito interessantes, continua a justificar-se, mas há seguramente espaço para a melhorar a vários níveis. E também para a aproveitar como instrumento de aproximação aos países ibero-americanos, o que nos parece justificar-se pela proximidade de culturas e línguas. Mais do que isso, a nossa ex periência de participação em projetos de cooperação no Brasil e em África constituiu uma mais valia que deveremos aproveitar, em nosso favor, no relacionamento entre a União Europeia, África e América do Sul. 0 conhecimento sobre estas realidades de que dispõe a nossa Escola poderá resultar num aumento da sua influência na Europa e em outras regiões do mundo e fazer dela um pivot muito importante no desenvolvimento da cooperação universitária, em particular da apoiada por programas europeus.

Mas, como dissemos, a escola tem hoje razões de sobra para assumir o desafio de se afirmar como um ator global, numa clara intenção de abertura ao mundo e de reforço de prestígio à escala mundial. Disto resultará a necessidade de construção de um equilíbrio, que é exigente, num compromisso entre a "cooperação para a excelência" e a "cooperação para o desenvolvimento". 
A primeira faz-se necessária para atingir os níveis de qualidade que são exigidos a quem quer ter um lugar entre os melhores e privilegia a investigação; a segunda, inscreve-se num esforço de apoio ao desenvolvimento dos povos, das comunidades e das instituições e privilegia a formação e a transferência de conhecimento (10).

Como é que o reforço da cooperação internacional poderá ser concretizado nas nossas políticas para o ensino e a ciência, num compromisso assumido de procura da excelência?

NO ENSINO

No ensino a Faculdade tem um desafio muito difícil.

Por um lado, precisa de assegurar as condições que the permitam continuar a dar passos em direção à excelência. 0 que passa por ter uma oferta formativa de grande qualidade, principalmente a nível pós-graduado, com docentes bem preparados, académicos experientes a acompanhar o percurso dos estudantes, e estudantes criteriosamente recrutados. E passa, também, por proporcionar aos estudantes: ambientes de estudo e de trabalho estimulantes, oportunidades de participação em redes colaborativas, contactos com especialistas internacionais, e possibilidades de interação com um vasto número de investigadores.

Por outro lado, a Faculdade precisa de assegurar os recursos financeiros que the permitam suportar a sua capacidade instalada, o que, nas presentes condições, não pode deixar de ser feito com medidas que não restrinjam excessivamente o acesso.

Isto é, a escola terá dificuldade em escapar a esta tendência para a massificação no acesso que se vem desenvolvendo há vários anos, com um elevado número de estudantes a concluir formações superiores e uma crescente procura por níveis de educação mais avançados(11). Mas, não pode esquecer também que, cada vez menos no futuro, qualquer escola ou universidade terá oportunidade de sobreviver sem uma forte aposta na qualidade, sem reforçar o seu prestígio, e sem defraudar a confiança daqueles que a procuram. Isto é, independentemente da sua orientação - para o ensino ou para a pesquisa -, a oferta formativa da Faculdade deve ter a excelência como desígnio, seja no plano científico, seja no plano pedagógico.

Terá assim que oferecer, a um mesmo tempo, cursos de grande qualidade, aspirando a criar uma forte reputação internacional, e cursos que assegurem a resposta a esta demanda sem precedentes no acesso à educação superior, que está a acontecer um pouco por todo o mundo e também no nosso país. Num compromisso que não é fácil sem os recursos docentes em quantidade suficiente para assegurar essa qualidade. Mas, é também sabido que num grande número de países existe uma oferta de pós-graduação que considera modelos de formação distintos: orientados para o ensino e orientados para a pesquisa; de orientação vocacional (profissionalizante) e de orientação não vocacional (académica)
A expansão da formação pós-graduada trouxe, de facto, grandes desafios às IES (12): transformação de sistemas de elite em sistemas massificados; dificuldades de financiamento de uma formação pós-graduada em acelerado crescimento; necessidade de assegurar a qualidade e reputação dos programas de formação num mundo cada vez mais competitivo; enorme diversidade de estudantes e de programas de pós-graduação.

Em síntese:

Pensando na internacionalização da nossa oferta formativa, ou daqueles cursos em que temos melhores condições para isso, o que deveremos fazer:

1. Apostar numa oferta formativa pós-graduada de grande qualidade orientada para a investigação, em particular ao nível de doutoramento: com critérios de recrutamento de estudantes mais apertados, com criação de ambientes de trabalho e de investigação estimulantes, com reforço da colaboração docente internacional, e recorrendo a uma utilização mais sistemática do inglês como língua de trabalho

2. Manter uma oferta formativa de índole profissionalizante, menos restritiva no acesso, mas com critérios de exigência pedagógica e técnico-científica cada vez mais elevados. Criando, em todos os cursos que oferece, independentemente da sua natureza, uma reputação de qualidade na formação susceptível de atrair um cada vez maior número de estudantes.

3. Em acordo com as melhores práticas internacionais, ter em consideração no desenvolvimento da nossa oferta formativa: (i) a adopção de normas e instrumentos institucionais que garantam a qualidade académica; (ii) a criação de quadros de referência para as qualificações (garantir a qualidade e proporcionar indicadores de comparabilidade e desta forma, facilitar a mobilidade de estudantes e o reconhecimento das formações); (iii) a definição de padrões de qualificação dos estudantes no acesso (assegurar que estes estudantes dispõem do potencial para ser bem sucedidos); (iv) um acompanhamento mais cuidado dos percursos dos estudantes durante as formações pós-graduadas; e (v) uma forte aposta na internacionalização dos programas (6).

Refira-se, a este propósito, que nas IES do Reino Unido os programas de pesquisa pós-graduados têm vindo a instituir um "Código de Prática", o qual integra um conjunto de documentos e instrumentos que procuram garantir os padrões académicos e as orientações definidas para as IES pela Agência para a Garantia de Qualidade no Ensino Superior (QAA$\mathrm{HE}$ ). Este código assume que cada IES deve dispor de sistemas próprios que permitam através de uma verificação independente, avaliar a qualidade, as orientações e princípios que promove, e a efetividade dos seus sistemas de garantia de qualidade (13)

4. Eleger um pequeno número de escolas/universidades internacionais (tendo em conta o prestígio dessas instituições) como parceiras privilegiadas na valorização da qualidade da nossa oferta formativa e discutir com elas a possibilidade de constituir formas de as- 
sociação ou parcerias estratégicas. A intenção primeira destas parcerias seria a oferta conjunta $\left(^{*}\right)$ de programas de doutoramento, com elevada qualidade, aproveitando de forma sinérgica as melhores recursos de cada escola ao serviço da qualidade dos programas.

5. Trabalhar com universidades escolhidas no contexto da constituição de parcerias estratégicas em apoio da "cooperação para o desenvolvimento", em particular na CPLE e no espaço ibero-americano. Trata-se, como atrás referimos, de dar passos no sentido de melhorar a cooperação atualmente existente e, também, de a aproveitar como instrumento de aproximação aos países ibero-americanos.

Estas parcerias teriam como objetivos prioritários a capacitação de recursos humanos e o apoio à criação de programas de formação pós-graduada nos países em desenvolvimento. Neste contexto fará sentido eleger como alvos prioritários na constituição dessas parcerias IES que, pela sua reputação nas regiões alvo, acrescentem valor a estes projetos: (i) universidades brasileiras nas parcerias para a cooperação com os países da CPLP; e (ii) universidades brasileiras e espanholas nas parcerias para a cooperação com os países da Ibero-América.

Não está, naturalmente, excluída a possibilidade de nestas parcerias considerar a participação de alguma universidade portuguesa, nem sequer universidades africanas dos países da CPLP ou ibero-americanas, que pela sua reputação nestas regiões, constituam mais valias para os projetos de cooperação.

6. Fazer um melhor aproveitamento institucional da mobilidade de docentes ao serviço desta estratégia de internacionalização no ensino, privilegiando como destinos prioritários das mobilidades as IES que são nossos parceiros estratégicos.

NA INVESTIGAÇÃO

"A Universidade do Porto dispõe hoje de uma forte rede de relações (formais e informais com IES e unidades de investigação de todo o mundo, entre as quais algumas das mais prestigiadas. E, no entanto, nem sempre esse relacionamento de trabalho tem sido valorizado a nível institucional e devidamente potenciado. Identificar esta rede de relações e envolver os membros da comunidade universitária mais prestigiados internacionalmente no apoio à internacionalização da Universidade, será uma forma de aproveitar a sua experiência e conhecimento e de dar força institucional a relações que já adquiriram uma grande relevância no plano individual ou de grupo" (10). 0 que também é verdade no que respeita à nossa Faculdade.

Já o sabemos: a colaboração internacional é um factor determinante do progresso da ciência e do reforço do prestígio e competitividade das instituições que a fazem. Faz, por isso, todo o sentido desenvolver esforços para encontrar parceiros internacionais e institucionalizar essas parcerias (redes colaborativas, consórcios, plataformas), dando-lhes visibilidade internacional e promovendo uma imagem de notoriedade. Mas isto deve ser feito sem prejuízo da liberdade que os investigadores devem ter, não apenas para desenvolver as suas ideias e projetos, mas também para definir as condições (incluindo a escolha de parceiros) em que umas e outros podem ser valorizados.

A aposta numa ciência competitiva e prestigiada a nível internacional exige, também, grandes recursos financeiros. Submeter candidaturas com sucesso junto das agências nacionais e internacionais de fomento da ciência é uma tarefa cada vez mais árdua, porque aumentou muito a competição entre os centros de investigação. Por isso, a criação de formas de colaboração com centros de investigação internacionais reforça a competitividade e, por via disso, as possibilidades de sucesso. E isto acontece "não apenas porque da simples constituição dessas parcerias resultam know-how e competências acrescidos que podem ser aplicados com vantagem na preparação das candidaturas e na gestão dos projetos, como também porque muitos dos programas de financiamento estabelecem como condição de elegibilidade a organização de consórcios internacionais" (10)

Promover uma mais estreita integração entre as formações de mestrado e de doutoramento e dos estudos de pós-doutoramento corresponde, também, a uma orientação com grande receptividade internacional no desenvolvimento da ciência (14)

0 acolhimento de estudantes de doutoramento e de investigadores de pós-doutoramento internacionais cria, também, um ambiente que favorece o trabalho de investigação. Relativamente aos primeiros, a criação de programas de doutoramento em associação com universidades estrangeiras, de que atrás falámos, é uma boa estratégia para os atrair. No caso dos postdocs, estes têm-se tornado elementos decisivos no aumento da produtividade científica e, por isso, a sua integração nas atividades de investigação da Faculdade deve ser reforçada. 0 seu número está a crescer rapidamente, prevendo-se que, dentro de uma década, possa existir mais de 1 milhão em todo mundo, em resultado do cada vez maior número de graduados com doutoramento (15).

primeiro Forum Humboldt sobre as perspectivas de carreira pós-doutoral, realizado em Washington em 2007, constatou que (15): os indivíduos com muito talento têm agora uma elevada mobilidade; os países estão a implementar de forma crescente medidas políticas para atrair investigadores estrangeiros e expatriados e a concentrar o seu investimento em potencial para a pesquisa (talento + instalações e equipamento + redes).

\section{Em síntese:}

Pensando no reforço da internacionalização da atividade de investigação, na nossa Escola, deveremos:

1. Preservar a liberdade dos investigadores e dos centros de investigação na definição das suas estratégias e políticas de desenvolvimento científico;

2. Aproveitar a sua experiência de participação em redes colaborativas, de gestão de ciência e de relacionamento internacional no apoio à definição e concretização de políticas para a internacionalização da ciência; 
3. Identificar, entre os melhores centros de investigação internacionais, um número restrito de parceiros que se predisponham a participar numa parceria estratégica, constituindo formalmente uma plataforma para o desenvolvimento da ciência e apostando no reforço da sua notoriedade internacional;

4. Reforçar a participação (e as condições de sucesso) em candidaturas às agências de financiamento, através da constituição de consórcios de centros de investigação muito competitivos, pelos resultados que já atingiram a nível internacional e pela experiência que adquiriram na participação e gestão de projetos internacionais;

5. Promover uma maior integração entre o treino científico pós-graduado e os estudos de pós-doutoramento e apostar na atração de estudantes e investigadores nacionais e internacionais com talento;

6. Constituir uma plataforma na internet que integre os ex-estudantes de pós-graduação e investigadores de postdoc da Faculdade. Esta rede terá entre os seus objetivos a revalorização da atividade científica a nível interno e da atividade colaborativa com outros centros de investigação e investigadores. Ao mesmo tempo, contribuirá para a valorização institucional do estatuto de investigador de postdoc e promoverá um reforço da visibilidade e notoriedade externa da investigação da Faculdade.

Nota:

${ }^{*}$ * A criação destes programas está confrontada hoje no nosso país com um quadro de alguma complexidade, no qual coexistem limitações de ordem jurídica e financeira que se constituem num obstáculo ao seu desenvolvimento. Existem, apesar de tudo, possibilidades de criação de programas conjuntos que ofereçam aos estudantes, em simultâneo, a possibilidade de obtenção do grau por mais do que uma universidade (se beneficiarem de apoios financeiros para estudar na outra universidade que surge associada ao programa), ou por uma única universidade, se não obtiverem esses apoios. Para isto ser possível, um mesmo programa numa área teria de estar acreditado como um programa oferecido pela Faculdade, e passar simultaneamente por um processo de acreditação que resultasse na criação de um programa conjunto.
1. Rauhvargers A. (2013). Global university rankings and their impact. Report II. EUA Reports on Rankings 2013. 2. Hazelkorn E (2009). Impact of Global Rankings on Higher Education Research and the Production of Knowledge. Occasional Paper No. 15. UNESCO Forum on Higher Education, Research and Knowledge. Paris UNESCO

3. Hazelkorn E, Loukkola T, Zhang T. (2014). Rankings in institutional strategies and processes: impact or lusion? EUA Publications 2014

4 Sursock A \& Smidt H (2010). Trends 2010: a decade 4. Surche in European Higher Education Belgium. EUA.

5. Gibney E (2013). A different world. Times Higher Education 31 January 2013, published online at http: www.timeshighereducation.co.uk/features/a-different-world/2001128.article

6. Marques A. (2017). Os desafios da universidade nos dias atuais e os 40 anos da pós-graduação da EEFEUSP. Revista Brasileira de Educação Física e Esporte. Número especial comemorativo dos 40 anos da pós-graduação da EEFEUSP: São Paulo: USP (In press).

7. Wächter B (2000). Internationalisation at home - the context. In: Paul Crowther, Michael Joris, Matthias Otten, Bengt Nilsson, Hanneke Teekens And Bernd Wächter. Internationalisation at Home. A Position Paper. Amsterdam: European Association for International Education (EAIE), pp. 5-13.

8. Knight $J$ (2008). Higher Education in Turmoil. The 8. Knight $J(2008$. Higher Edcation in Tumain 9. IAU (2013). Affirming Academic Values in Internationalization of Higher Education: A Call for Action. In: IAU Re-thinking Internationalisation. 2/4/2013).

10. Santos JCM, Silva AF, Marques AT, Agra C, Laranjo F, Proença J, Correia JA, Ferreira MA, Marinho MF, Azevedo SF (2014). Cooperação. Documento de Orientação Estratégica. Universidade do Porto.

1. British Council (2013). Megat 11. British Counct (2013). Megatrends. The future of

2. Clarke G \& Lunt I (2014). International comparsons in postgraduate education: quality, access and employment outcomes. Report to HEFCE (Higher Education Funding Council for England) September 2014 UK: University of Oxford.

13. QAAHE. Code of practice for the assurance of academic quality and standards in higher education Section 1: Postgraduate research programmes - September 2004. UK: Quality Assurance Agency for Higher Education
14. Thune T, Kyvik S, Sörlin S, Olsen TB, Vabø A \& Tømte C (2012). PhD education in a knowledge society. An evaluation of PhD education in Norway. Report 25/2012. Oslo: Nordic Institute for Studies in Thnovation, Research and Education

15. Gallagher M (2013). Postdocs and Changing Researcher Career Paths. In: Helmut Schwarz \& Peter Chen, Postdoctoral Career Paths 2.0: The Golden Triangle of Competitive Junior Investigators, Adequate Academic Systems, and Successful Careers. Proceedings of the 7th Forum on the Internationalization of Sciences and Humanities, Berlin: Dr. Josef Raabe Verlags-GmbH, pp. 6-16. 